\title{
An Overview of Factitious Disorders
}

L. Moreno ${ }^{\#}$, M. Pereira Alves ${ }^{2 \#}$, S. Penedos ${ }^{1}$, A.M. Franco ${ }^{1}$, I. Fonseca ${ }^{1}$, N. Ribeiro ${ }^{1}$, M.J. Freire ${ }^{1}$, J. Vieira ${ }^{1}$, J. Nogueira ${ }^{1}$,

R.S. Ribeiro ${ }^{3}$, L.L. Duarte ${ }^{4}$, S. Mendes ${ }^{1}$, A. Gamito ${ }^{1}$.

${ }^{1}$ Setúbal Hospital Center, Department of Psychiatry and Mental Health, Setúbal, Portugal. ${ }^{2}$ Central Lisbon University Hospital Center, Area of Child and Adolescent Psychiatry, Lisboa, Portugal. ${ }^{3}$ Arrábida Local Health Unit, Luísa Todi Family Health Unit, Setúbal, Portugal. ${ }^{4}$ Matosinhos Local Health Unit, Oceanos Family Health Unit, Matosinhos, Portugal. \# These authors contributed equally to this work.

\section{Background and Aims}

\section{According to} DSM-5

Factitious disorder imposed on self: "Falsification of physical or psychological signs or symptoms, or induction of injury or disease, associated with identified deception... in the absence of obvious external rewards".

\section{Factitious disorder imposed on another}

Munchausen syndrome is one form of factitious disorder that is severe (with physical symptoms) and chronic.

\section{Munchausen syndrome}

by proxy(especially a child)
The term Munchausen syndrome was coined in 1951 after Baron ivon Munchausen, a storyteller known for "his wild retellings of " exaggerated exploits.

These disorders cover a multitude of clinical and non-clinical behaviors ranging from symptom exaggeration to deliberate feigning. A gradient of behaviors is arrayed which places disease simulation at one end of a spectrum, with the other end anchored by 'real' disease.

\section{Objectives}

This review aims to provide a brief overview of factitious disorders, regarding the origin, spectrum disorder, differential diagnoses and associated psychological factors.

\section{Materials and Methods}

A non-systematic literature review, using PubMed search with the terms "factitious disorders with psychological symptoms", "factitious psychological presentations" and "factitious disorders and malingering".

\begin{tabular}{|c|c|c|c|}
\hline \multicolumn{2}{|c|}{ Results } \\
\hline Clinical red flags \\
allergies Few visitors in an inpatient setting \\
Extensive medical history not supported by diagnosis or medical procedures
\end{tabular}

In about $60 \%$ of cases: a young $\$$ with an occupation related to healthcare or the laboratory. Commonly have a history of abuse, neglect, unstable childhood environments and suffer from low self-esteem.

Diagnostic process

Excluding organic disease

An unusual presentation of a common medical condition

\section{Excluding} somatoform disorders

Generated unconsciously
- The motivation is external (financial gain, avoiding legal difficulties...)

- It is not considered a mental illness, but receives a $\mathrm{V}$ code in DSM-5

- The motivation is internal, responding to psychological drives (the need for attention or to reduce loneliness)
Factitious
disorders consciously

\section{Psychology of factitious disorder - Multiple theories..}

- Masochistic attempts in order to cope with guilt that may exist as part of abuse history

- The uncertainty about the validity of subjective experiences, assuming a false identity and reifying inner experience through physical symptoms

\section{Conclusions}

The boundaries between factitious disorder, somatization and malingering are often unclear. External and internal motives may coexist and vary over time in the same perpetrator.

The establishment of a therapeutic relationship is the most important and most difficult task in these patients. Psychopharmacologic treatment for factitious disorder and evidence for its efficacy remain lacking, as psychotherapy is considered to be first-line treatment.

However, such patients are frequently unmotivated to engage in psychotherapy and may be at particular risk for complications as overt self-harm behavior and psychosis.

\section{References}

1- Tatu, Laurent, Selma Aybek and Julien Bogousslavsky. "Munchausen Syndrome and the Wide Spectrum of Factitious Disorders." Frontiers of neurology and neuroscience42 (2018): 81-86.; 2- Jafferany M, Khalid Z, McDonald KA, et al. Psychological aspects of factitious disorder. Prim Care Companion CNS Disord. 2018.20(1):17nr02229.; 3- Bass, C. and D. T. Wade (2019). "Malingering and factitious disorder." 19(2): 96-105.; 4- Abeln, B. and R. Love (2018). "An Overview of Munchausen Syndrome and Munchausen Syndrome by Proxy." Nurs Clin North Am 53(3): 375-384.; 5- Harold Spivak, Gary Rodin, Amanda Sutherland. The Psychology of Factitious Disorders: A Reconsideration. Psychosomatics 35 (1994): 25-34. 